\title{
Au decorated ZnO thin film: application to DNA sensing
}

\author{
K. L. Foo ${ }^{1} \cdot$ U. Hashim ${ }^{1}$ C. H. Voon ${ }^{1} \cdot$ Mohammad Kashif $^{2} \cdot$ Md. Eaqub Ali ${ }^{3}$
}

Received: 18 January 2015 / Accepted: 5 May 2015

(C) Springer-Verlag Berlin Heidelberg 2015

\begin{abstract}
Here we reported the gold nanoparticles (GNPs) decorated $\mathrm{ZnO}$ thin films based biosensor for the detection of pork DNA hybridization. Label-free DNA detection is increasingly important in bio diagnostics, food analysis and forensic investigations. The capacitance, permittivity and impedance profiles of the biosensor clearly differentiated the complementary and non-complementary target DNA detection using low-cost dielectric analyzer. In this study, GNPs were used to create an attachment surface between the $\mathrm{ZnO}$ thin films and the thiol-modified probe DNA and to enhance the sensitivity of the biosensor up to $\sim 59 \%$. The $\mathrm{ZnO}$ thin films and $35 \pm 5 \mathrm{~nm}$ in diameters of GNP-coating on their surfaces were confirmed with various types of measurement such as FESEM, XRD, EDX and UV-Vis spectroscopy.
\end{abstract}

\section{Introduction}

DNA hybridization detection is a key issue in molecular bio diagnostics (Ali et al. 2012c), determination of genetic diversity (Hood and Galas 2003), criminal investigation in forensics and immigration (Heller 2002), food analysis (Ali et al. 2012b, d) and environmental monitoring (Ali

K. L. Foo

klfoo@unimap.edu.my

1 Nano Biochip Research Group, Institute of Nano Electronic Engineering (INEE), Universiti Malaysia Perlis (UniMAP), 01000 Kangar, Perlis, Malaysia

2 Faculty of Engineering, Universiti Malaysia Sarawak, 94300 Kota Samarahan, Sarawak, Malaysia

3 Nanotechnology and Catalysis Research Centre, Universiti Malaya, 50603 Kuala Lumpur, Malaysia et al. 2012c). Various techniques have been proposed for the detection of target DNA, such as electrochemical sensing (Zhang et al. 2008), surface plasma resonance (Byun et al. 2011), fluorescence (Selinger et al. 2000), chromatography in tandem with mass spectrometry (Farmer et al. 2005), oligonucleotide microarray and DNA (Ali et al. 2012c). However, most of them are expensive, involve multiple steps, need sophisticated instrumentations and highly skilled manpower and thus they are not suitable for general applications.

Metal-oxide-thin-films with semiconducting properties have currently received considerable attention because of their convenient and useful electrical and optoelectronic properties which are suitable for diversified applications (Fan and Freer 1993; Ghosh et al. 2006). ZnO thin films are particularly interesting because of their wide band-gap $(\sim 3.37 \mathrm{eV})$, high exciton binding energy $(\sim 60 \mathrm{meV})$ and long-term stability (Jie et al. 2004; Johnson et al. 2003). Recently, $\mathrm{ZnO}$ thin films have been applied a in various sensors, (Fulati et al. 2010; Usman Ali et al. 2010), ultraviolet detector (Chai et al. 2009) and chemical and gas sensors (Baratto et al. 2008; Shen et al. 2005). However, very little attention has been paid to detect nucleic acid hybridization using $\mathrm{ZnO}$ thin films.

Various methods, including sol-gel spin coating (Kashif et al. 2012), physical vapor deposition (PVD) (Wang et al. 2005), chemical vapor deposition (CVD) (Li et al. 2003), spray pyrolysis (Ashour et al. 2005), sputtering (Deng et al. 2007), anodizing (Voon et al. 2014) and ink-jet printing (Shen et al. 2005) have been proposed for the synthesis of $\mathrm{ZnO}$ thin films. In this study, sol-gel spin coating technique was chosen because of its low-cost, chemical composition control, low-temperature annealing and homogeneity (Habibia and Sardashtia 2008; Kamaruddin et al. 2010; Kashif et al. 2012). Prior to the probe DNA immobilization 